UDC: 821.134.2.09 Mesía Á.

821.134.2.09 Santa Cruz J.

DOI: https://doi.org/10.18485/beoiber.2018.2.1.7

\author{
José Luis Eugercios Arriero' \\ Universidad Autónoma de Madrid \\ España
}

\title{
CORTESANOS DEL AMOR PRETÉRITO: OTRA VUELTA SOBRE EL "DONJUANISMO" DE ÁLVARO MESÍA Y JUANITO SANTA CRUZ
}

\begin{abstract}
Resumen
La configuración de Álvaro Mesía y Juanito Santa Cruz conforme al arquetipo donjuanesco no es ideológicamente neutra ni obedece sin más a un tópico galante, sino que les sirve a Clarín y Galdós para ilustrar el papel pernicioso, la burla si se quiere, del estamento burgués en el contexto de la Restauración. Pero la adecuación del mito a un ambiente urbano, sea Madrid o Vetusta, lo modifica de manera radical: por ello, el joven Santa Cruz termina su novela convertido en poco menos que una sombra atropellada por la historia de ese Madrid galdosiano que se está haciendo; mientras que Mesía es, en una Vetusta casi medieval, el único personaje que, a la postre, no queda destruido.
\end{abstract}

Palabras clave: “donjuanismo», Álvaro Mesía, Juanito Santa Cruz, Pérez Galdós, Clarín.

\section{COURTIERS OF PRETERITE LOVE: ANOTHER ROUND ABOUT THE “DONJUANISMO» OF ÁLVARO MESÍA AND JUANITO SANTA CRUZ}

\begin{abstract}
The configuration of Álvaro Mesía and Juanito Santa Cruz according to the archetype of Don Juan is not ideologically neutral or obedient to a gallant topic, but serves Clarín and Galdós to illustrate the pernicious role of the bourgeois state in the context of the Restoration. But the adaptation of the myth to an urban environment modifies it in a radical way: for this reason, the young Santa Cruz ends his novel turned into a shadow run over by the history of Madrid that is being made; while Mesía is, in an almost medieval Vetusta, the only character that is not eventually destroyed.
\end{abstract}

Key words: "donjuanismo", Álvaro Mesía, Juanito Santa Cruz, Pérez Galdós, Clarín.

1jeugercios@gmail.com 


\section{Don Juan transfigurado: caracterización donjuanesca del señorito}

Cada tiempo añade una nueva perspectiva desde la que contemplar los mitos de siempre; o podría decirse, quizás, que los mitos de siempre ofrecen una nueva perspectiva para el tiempo presente. Como fuera, lo cierto es que de común la novedad de una época no reside tanto en crear tipos literarios como en reinterpretarlos en función de los nuevos contextos. Cuando Clarín y Galdós perfilan, respectivamente, a don Álvaro Mesía y a Juanito Santa Cruz, es obvio que lo hacen a la luz del mito de Don Juan², cuyo arquetipo canónico había fijado dos siglos antes el Burlador de Sevilla. La burla donjuanesca, trazada de modo programático por Tirso, la llevaría a sus últimas consecuencias, ya en el Romanticismo, un casi satánico Félix de Montemar, y era difícil ir más lejos. Cabía, eso sí, adaptarla a una nueva circunstancia y a unos nuevos modos narrativos. Es lo que hacen Galdós y Clarín en un momento en que la convulsa realidad sociopolítica española está precipitando el final de la moral caballeresca que podía representar, por ejemplo, el galdosiano conde de Albrit en El abuelo (v. Mora García 1981: 82), y todo parece encaminarse hacia esa farsa canovista que terminará por traicionar los dogmas revolucionarios liberales bajo la apariencia de una democracia coronada (v. Seco Serrano 1973: 284-285). Viejos absolutos como la religión o lo patriótico van derivando hacia una preocupación social cada vez más explícita, y en parte por ello asistimos por estos años a la eclosión de la novela realista-naturalista ${ }^{3}$, género urbano y burgués, escrita por la burguesía y para la burguesía ( $v$. Rodríguez Puértolas 2000: 319-3204), y que se antoja un instrumento particularmente propicio cuando de representar la cuestión social se trata. Mesía y Santa Cruz son dos donjuanes que pasan del verso a la prosa, del drama a la novela, y del cronotopo difuso y casi mítico a una contextualización social bien concreta.

Aceptaremos, con Zorrilla, que el Don Juan se define en el acto mismo de la seducción: "uno para enamorarlas, otro para conseguirlas, otro para abandonarlas" 5 . Es, por tanto la negación del compromiso marital. Cuando el danés Sören Kierkegaard lo toma como paradigma del estadio estético de la existencia lo opone al hombre ético,

2 Para el caso de Juanito Santa Cruz puede consultarse, entre la abundante bibliografía, el trabajo de Andreu (1989). Respecto a Mesía, Ubach Medina (1996) ha estudiado las referencias directas del personaje clariniano al Don Juan de Zorrilla.

3 Por encima de polémicas de otro tiempo acerca del naturalismo español, en estas páginas consideraremos que Galdós y Clarín, en el periodo que nos ocupa, conforman por pleno derecho una suerte de paradigma realista-naturalista. Véase al respecto el trabajo de Caudet Roca (2002).

${ }^{4}$ El llorado profesor Puértolas prefirió siempre, en sus clases, decir contra la burguesía; pero, como él mismo reconocía, este contra sería difícilmente aplicable a los Valera, Pereda y demás narradores realistas de orientación más conservadora o menos subversiva.

${ }^{5} \mathrm{O}$ «burlar, halagar, raptar, violentar y pasar corriendo", que diría Vossler (1995: 100) comentando al personaje de Tirso.

BEOIBERÍSTICA Vol. II / Número 1 (2018) | 99-112 
personificado en la figura del esposo ${ }^{6}$. Por simplificar las cosas, el hombre ético concibe el tiempo como historia, y tiende por ello al compromiso, mientras que para el esteta, el Don Juan, la eternidad se condensa en el instante. Por ello, sumido en la indiferencia estética, ama sin conciencia ni arrepentimiento y puede, una vez consumada la burla, abandonar la pieza a su suerte, y huir siempre para romper cualquier vínculo con lo sucedido: "si lo que yo quiero - se queja un lastimero Santa Cruz - es borrar un pasado que considero infamante; si no quiero tener ni memoria de él” (Pérez Galdós 1992: 206). Juanito es, desde una perspectiva kierkegaardiana, negación de la historia.

El joven Santa Cruz, siempre ocioso e improductivo, perfectamente encarnaría, si bien a la manera de una inversión paródica, a aquel "gran seductor de nuestra tierra, ingenioso, pérfidamente amable, escéptico hasta el cinismo" (Pérez Galdós 1868) que describe el novelista canario a raíz del estreno de la ópera Don Giovanni en Madrid. Recuérdese cómo sus ansias de seducción, su voracidad dirá Montesinos (v. 1980: 219), dan verdadero inicio a la novela: "vio algo que de pronto le impresionó, una mujer bonita, joven, alta", y a él, "que no pecaba de corto [...], diéronle ganas de tomarse confianzas con ella" (Pérez Galdós 1992: 181-182). Se cansa pronto, claro, pero no sin antes haberle dado a la Izquierdo "palabra de casamiento con reserva mental de no cumplirla, una burla, una estafa, una villanía" (Pérez Galdós 1992: 207-208), tal como se lo confiesa a Jacinta, su esposa, esa otra víctima que igualmente "se dejaba alucinar por las dotes seductoras de su marido" (Pérez Galdós 1992: 237). Y así, amparado en todo momento por su clase ${ }^{7}$, atraviesa la novela ejerciendo una perniciosa acción corruptora sobre todo aquello que toca, con la despresocupación siempre de alguien en quien "el amor propio descollaba [...] sobre la conciencia y sobre los sentimientos de todos" (Pérez Galdós 1999: 59).

El Mesía de Clarín, igualmente configurado conforme al tipo donjuanesco, se nos presenta como un advenedizo "que no es noble, pero anda con ellos" (Alas "Clarín" 1997: $213)^{8}$, y que, sin embargo, controla los resortes de la alta sociedad provinciana, ayudado nuevamente por una habilísima capacidad seductora que ejerce en todos los planos: como el consumado embaucador que es, lo mismo acata el "sport y catolicismo" del nuevo régimen que se finge romántico enamoradizo ante el primogénito de los Vegallana9. Sin embargo, al contrario que el Juanito galdosiano, Mesía no ejerce su seducción entre las masas populares del barrio del Sol (v. Concejo 1993: 253), sino que

6 La filosofía de Kierkegaard no pasa aquí de pretexto o instrumento, y no es este lugar para desarrollar ni estos dos estadios ni el tercero, el religioso, que bien poco tendría que ver con nuestro negociado. Recordaremos, no obstante, la propuesta de José Luis Cañas (2003), para quien la teoría kierkegaardiana se sustentaba sobre dos maneras de desenvolverse la vida humana: inmediatez y relación.

7 Recibe, en efecto, la aprobación de don Baldomero y Barbarita, aunque tal vez resulten más interesantes los desvelos de Guillermina Pacheco por salvaguardar el buen nombre del Delfín.

8 Y en otra parte apunta el narrador que "no tenía el acento del país" (Alas "Clarín" 1997: 243).

9 Quien, pretendido émulo de don Álvaro, se deja engañar "como engañaba [Mesía] a ciertas mujeres que tenían educación y sentimientos semejantes a los del marquesito" (Alas “Clarín” 1997: 252). 
escoge mujeres con educación y sentimientos semejantes a los del marquesito, y de similar extracción social. También es cierto que la presencia de los bajos fondos en La Regenta es prácticamente circunstancial, o al menos no tan determinante como en la obra de Galdós, pero en cualquier caso la burla de Mesía apunta a la alta sociedad vetustense ${ }^{10}$. $Y$ así, en el contrapunto constante con una figura tan poderosa como la del Magistral se explicita la disociada moral vetustense, donde dos fuerzas contrapuestas, el catolicismo biempensante y una sexualidad no siempre soterrada, parecen encontrarse no se sabe si en continua pugna o en connivencia.

Nada hasta aquí, se dirá, que invierta el código arquetípico donjuanesco. Sucede, sin embargo, que Galdós y Clarín han tomado al tipo donjuanesco de los dramas románticos y lo han insertado en sociedad. Frente al radical subjetivismo romántico se proponen, en clave cervantina si se quiere, dar razón de la realidad social aplicando una pluralidad de perspectivas, y ello implica que el Don Juan no es ya la figura central en torno a la cual todo gira, sino un agente social más. Los demás personajes tienen ahora voz, perspectiva y mundo interior. También las burladas, Ana Ozores y Fortunata Izquierdo, cuya relación con el burlador transciende la burla convencional para convertirse en dialéctica de clases. ¿Cómo ocurre esto? Porque, en cierto modo, Galdós y Clarín están poniendo de manifiesto las lacras que un determinado sistema socio-moral provoca en las burladas y en lo que representan pero, al tiempo, atisban una alternativa: más real en el caso del primero, asumimos que más cuestionable en el del segundo.

En el caso de Mesía y la Regenta, es verdad que Ana es burlada y cosificada, pero no es menos cierto que también se le ofrece un sucedáneo de redención: se le ofrece, en la figura de su burlador, la posibilidad de por vez primera unificar cuerpo y espíritu, sus afectos y sus insatisfechas ansias carnales ${ }^{11}$. De ahí que la entrega al burlador tenga, paradójicamente, un punto de reivindicación, de lucidez y conquista. Cosa similar ocurre con Juanito Santa Cruz, a quien Fortunata Izquierdo convierte en su idea, o al menos en parte de su idea. Lo perseguirá durante toda la novela como mujer enamorada, pero no es tampoco la dama despechada de los dramas románticos: a Fortunata no la mueve ya un fervor dócil, sino la firme convicción de esa idea suya de ser verdadera esposa. Idea que defiende y argumenta contra todo prejuicio, contra toda convención; idea que en todo sobrepasa la pueril perspectiva de un personaje como Juanito, cuyo diminutivo da ya razón de lo mínimo del personaje.

Por consiguiente, la dialéctica burlador-burlada descrita por Clarín y Galdós sí invierte los tópicos heredados del romanticismo. El Don Juan tradicional es perseguido por una dama burlada a quien solo mueven amor y despecho. Ana Ozores y Fortunata se aferran igualmente a sus burladores, pero instadas por una fuerza narrativa de más peso que el despecho: su persistencia en un amor prohibido tiene mucho de reacción social. El adulterio de Ana Ozores es rebelión contra una institución burguesa - el matrimonio de

10 Donde, por cierto, aspectos como su permisividad en materia sexual o su escepticismo religioso no dejan de suponer, justo es reconocerlo, un cierto aire de modernidad (v. Concejo 1993: 148).

${ }^{11}$ Véanse al respecto las consideraciones de Beser (1982: 70) y Vilanova (2001: 172). 
conveniencia - denuncia de una doble moral alienante y breve restauración de esa unidad que le han robado. El de Fortunata Izquierdo cuestiona, y hace que se tambaleen, los cimientos mismos de la alta burguesía madrileña encarnada en los Santa Cruz, al reivindicar una idea que está por encima de clases. ¿Qué queda de Mesía y Juanito? Por de pronto, su talla moral es ínfima en comparación con la de Ana y Fortunata. En relación con ellas, se ven privados de toda trascendencia. Ni rastro ya del alter deus Félix de Montemar; ni posibilidad de una redención por el amor, como hiciera Zorrilla con su Tenorio. Mesía y Juanito son dos señoritos, dos advenedizos que se van perdiendo en la novela sin profundidad ni dramatismo, como lacra coyuntural de una sociedad enferma. Pero, veremos, no de la misma manera.

\section{Don Juan enmarcado: de Vetusta a Madrid}

Por encima de las evidentes peculiaridades que distinguen a Galdós y a Clarín como novelistas, es indudable que durante su periodo de más firme adscripción a los cánones realistas-naturalistas comparten una preocupación radical por la cuestión social. No son las suyas novelas estrictamente de personajes, o no solo, sino que tanto Fortunata y Jacinta como La Regenta entrañan una particular manera de contemplar la sociedad, de modo que todo en ellas, también los personajes, cobra sentido pleno sólo en la medida en que se pone en relación con el contexto.

Esto es más evidente en Galdós, para quien se presenta la sociedad como "una estructura dinámica, un ser vivo que tiende a subsistir como principal misión" (Mora García 1981: 74). Los avatares de la familia Santa Cruz, de los Rubín, el desencanto lúcido de Feijoo o los mismos asuntos del Cuarto Estado se comprenden en el marco creativo de una ciudad, Madrid, cuyo desarrollo se ve afectado por la actividad de quienes la habitan. En esta sociedad dinámica, cuya dialéctica está percibiendo ya Galdós, el joven Juanito comienza a ser un personaje anacrónico. De una parte, representa a quienes frenan el cambio, no en vano en la misma saga Santa Cruz es él quien ralentiza el progreso de la familia amenazando con dilapidar tanto el capital heredado como la educación recibida. De otra, como se pone de manifiesto en su paso por la Barcelona industrial, no parece darse del todo cuenta de que la sociedad está evolucionando ( $v$. Rodríguez Puértolas 1975: 38-39). En cualquier caso es, desde la perspectiva galdosiana, alguien de otro tiempo. Cierto que el Madrid de Galdós es todavía aquel poblachón manchego tan distante de las grandes urbes industriales europeas, de la misma Barcelona que conoce el Delfín en su viaje de novios; pero nuestro novelista, "imagen de la vida es la novela"12, retrata lo que ve. $Y$ lo que ve, o al menos intuye aunque tal vez no sepa tasarlo en su justa medida, es que late en la ciudad un convulso dinamismo interno: de

\footnotetext{
12 Según pronunció en su discurso de ingreso en la Real Academia (v. Caudet Roca 1988: 273).
} 
repente, los distintos estratos sociales son no ya compartimentos estancos, sino fuerzas en tensión, y el encuentro entre el señorito Santa Cruz y Fortunata trasciende los moldes folletinescos con que Galdós nos los cuenta para adquirir la categoría de metáfora social, la del encuentro dialéctico entre dos clases ${ }^{13}$. Dialéctico porque Fortunata saldrá transformada de ese encuentro, sin que pueda saberse a ciencia cierta si del todo derrotada, puesto que Galdós, a fin de cuentas, tampoco sabe bien hacia dónde conducen los procesos de que intenta dejar constancia en su obra. Sí parece saber, en cambio, que estos procesos le están cogiendo con el pie cambiado a la burguesía, que sigue mandando, sí, pero que no tiene ya el dominio absoluto del panorama social. Y que, desde luego, no termina de comprenderlo por completo.

Así se explica la tipología de Juanito Santa Cruz, un "personaje plano, que no progresa, no aprende, que no se busca a sí mismo ni resulta conflictivo, y no le interesa la búsqueda de valores en su mundo" (Acosta de Hess 1988: 77). No es inofensivo, no puede serlo, lo exigen tanto el dramatismo folletinesco de la novela como el afán galdosiano por reflejar la acción de la burguesía en el ámbito social; pero sí es un arquetipo llamado a la superación. A Galdós le gustan más, qué duda cabe, el Agustín Caballero de Tormento o el mismo Evaristo Feijoo - no deja de ser otro seductor - que alecciona a Fortunata: "por de pronto, de lo que yo trato es de que sea usted práctica" (Pérez Galdós 1999: 92). Fortunata, como esa clase popular que aspira a hacerse oír, aprenderá a ser práctica, evolucionará, pero Juanito no. Quizás por ello, Fortunata y Jacinta es intuición de un tiempo venidero que no será ya el suyo, y hacia el final de la novela, próxima ya la muerte de Fortunata Izquierdo, Juanito Santa Cruz no es más que una sombra apenas iluminada por la idea de quien sin embargo le sigue amando.

En Clarín todo esto resulta menos claro, en gran medida porque Vetusta no ofrece un marco tan dinámico o, al menos, su dinamismo nos pasa más inadvertido. Como ya se indicó, la presencia de las clases bajas resulta bastante secundaria, no diremos que ociosa, quizás porque Clarín no se centra tanto en la dialéctica de clases sociales - lo que sí era patente en Galdós - como en la corrupción de una de ellas: "los fracasos y aspiraciones, dirá Gold, de la sociedad de clase media de la Restauración" (1989: 1287). En la misma línea incide Antonio Vilanova (1987: 353) cuando define Vetusta como una "verdadera suma novelesca de la vida provinciana, que tiene como escenario el ambiente corrompido e hipócrita de una vieja ciudad levítica en el marco social e histórico de la España de la Restauración": Alas, aunque alejado de la vorágine madrileña, compartía el desencanto galdosiano hacia una clase media poco comprometida con el desarrollo social, y hace de la ciudad metáfora de su tiempo. La atmósfera de Vetusta, densa y cerrada, casi gótica, dice de una ciudad encerrada en sí misma. A Clarín, menos provinciano que sus personajes, no se le escapa el mundo exterior - la política capitalina o esa moda que Mesía compra en París - pero su Vetusta parece permanecer al margen, y

13 Véase al respecto la interpretación en clave socio-histórica que de la novela hace Francisco Caudet ( $v$. Pérez Galdós 1992: 51-65), para quien la trama folletinesca es calco del proceso que conduce a la restauración borbónica.

BEOIBERÍSTICA Vol. II / Número 1 (2018) | 99-112 
encontramos, a la hora de la verdad, una burguesía casi feudal, endogámica, ajena a todo lo que no sean sus propias preocupaciones. La dialéctica de clases esbozada por Galdós se verá reducida aquí a un cúmulo de intrigas palaciegas en que se desenvuelven, con desigual suerte, los personajes.

Sin renunciar a la crítica social, da la impresión de que Clarín ha intentado con su Vetusta componer la atmósfera adecuada para la historia que tiene en mente. De ahí ese tiempo circular, esa monotonía en la que la tristeza aparece "a la hora de siempre" (Alas "Clarín" 1997: 439). Madrid se está haciendo, Vetusta es una cárcel en que no se atisba la posibilidad de cambio. En Madrid una nueva clase parece insinuarse como alternativa; no así en Vetusta, cuyas intrigas y veleidades giran siempre en torno a los puntos neurálgicos del casino, el palacio de los Vegallana y la catedral. En Madrid pueden coexistir, aunque no en igualdad, distintas alternativas morales. En la Vetusta que Clarín desmenuza - la otra, la del Barrio del Sol, interesa menos - una clase dominante impone sus cánones sin posibilidad de respuesta: sólo un matrimonio de conveniencia le ha permitido a la Regenta integrarse ( $v$. Vilanova 2001: 83), aun a costa de su propia destrucción. Cuando Ana Ozores se rebele, porque su adulterio tiene ese punto de rebelión, lo hará a título individual y no encarnando en su persona, como Fortunata, las posibilidades de una clase entera. Fortunata es el pueblo que logra hacerse oír, aunque no entender, por Guillermina y por Jacinta, por el mismo Nones. Frente a esa Regenta sin identidad (esposa de Quintanar, dirigida del Magistral), es en sí misma una alternativa al orden establecido. Su adulterio hace temblar una institución burguesa, el matrimonio canónico de Juanito y Jacinta y todo lo que implica; el adulterio de Ana Ozores, incluso con su real carga subversiva, termina por quedarse en un divertimento para la burguesía vetustense. Recordaremos que el encuentro entre Juanito Santa Cruz y Fortunata se había producido en la Cava de San Miguel, porque preludiaba un encuentro entre clases. El primero entre Ana y Mesía, en el casino, precede a un adulterio auspiciado por la misma clase de ambos, de manera que para la Regenta el camino de salida de Vetusta conduce, a la postre, a Vetusta misma.

Llegados a este punto, quizás adquiera la figura de Álvaro Mesía una dimensión más compleja de lo que a menudo se viene pensando. Vale que esto entra en conflicto con el código donjuanesco tal como lo hemos planteado, y que el personaje resulta, sobre todo en su contraste con De Pas, un tanto simplón y paródico ${ }^{14}$; pero es también un auténtico poder fáctico en la ciudad porque representa, e incluso quintaesencia, las aspiraciones de su provinciana burguesía. Si el adulterio de Fortunata atentaba contra el status quo burgués, el de Ana Ozores viene a confirmar su poder omnímodo: es un triunfo de esa burguesía ociosa y decadente que personifica Mesía. Se consuma de este modo un círculo vicioso: el adulterio de Ana viene dado por sus sentimientos, sí, pero

14 Es ese don Juan ya entrado en años que incluso debe hacer ejercicio para recobrar el vigor tras los excesos amatorios. 
también "por la envidiosa complicidad del medio social en que se mueve" (Vilanova 2001: 62). Vetusta ha creado el problema, un matrimonio de conciencia; Vetusta ha tolerado una penitencia tan perniciosa como pueda ser la dirección espiritual del Magistral; y Vetusta le ha ofrecido a la Regenta una salida en los brazos de Álvaro Mesía, en los brazos del presidente del Casino. De manera que Ana está predestinada: todo en ella, traumas, caídas, e incluso el breve éxtasis amatorio, se lo debe a Vetusta. Todas las aparentes alternativas que se le presentan (el matrimonio con Quintanar, la caída con don Álvaro, la comunión con De Pas) integran, a la postre, una misma espiral viciosa, un continuo retorno a su condición esencial de mujer problemática, porque no hay real alternativa en Vetusta. Madrid, al contrario que la ciudad clariniana, es ámbito de la posibilidad. Galdós, que escribe a la sombra del fracaso de la Gloriosa, ha perdido la fe en que su clase burguesa pueda cambiar, pero intuye que en la sociedad madrileña van insinuándose otras fuerzas, mientras que el mismo aire viciado de la sociedad vetustense garantiza la pervivencia de un status quo contra el que nadie puede revelarse. Lo hace Ana y queda destruida; lo hace incluso, a su modo, De Pas y termina igual. Pero Madrid es otra cosa: a la Regenta ningún Feijoo le ha enseñado a ser práctica, ninguna Mauricia le ha dado conciencia de su fuerza, porque la Vetusta de Alas no tiene personajes de este calado.

Vetusta y Madrid no son la misma cosa, ni pueden serlo sus donjuanes, que solamente se comprenden pasados por el tamiz de lo social, esto es como materialización de una postura burguesa ante la política restauradora, los códigos sociales, la moral establecida y el papel de la mujer. Ambos tienen, pues, mucho de encarnación simbólica del contexto en que se integran, solo que en el caso de Clarín se trata de un contexto único: por ello, al final, es Vetusta quien se impone, en la figura de Álvaro Mesía, con los Vegallana de fondo. En el Madrid de Galdós existe un amplio espectro social, un panorama en el que Fortunata puede crecer, transformarse. Aprende de Feijoo, de Mauricia, del mismo Maxi, y llega así a convertirse en un problema real para el clan de los Santa Cruz. Si la caída de Ana fue auspiciada por Vetusta, la pícara idea de Fortunata hace que se tambalee un matrimonio $y$, por ende, una estructura burguesa ( $v$. Acosta de Hess 1988: 86). Ana Ozores ha chocado contra los muros del status quo burgués, mientras que Galdós ha señalado sus límites: los trasciende la idea de Fortunata, como los trasciende la lucidez de don Evaristo, como los trasciende la locura misma de Maxi entrando en el manicomio.

\section{Don Juan burlado: la historia como superación}

El tipo donjuanesco, insertado en un ámbito social, modifica sus rasgos de manera que se convierte en ciudadano. Mesía y Juanito Santa Cruz han adquirido la categoría de elemento social, llegando al punto de expresar los rasgos de un colectivo, de una clase. 
Por ese motivo están psicológicamente menos trabajados ${ }^{15}$ : los suyos no son los avatares de un individuo, sino los de la clase que encarnan. Pero no dejan por ello de ser donjuanes. Se antoja preciso, pues, acotar la función social que desempeñan, que es tanto como decir la naturaleza de su burla. El Don Juan clásico tenía en la burla su propio fin; ahora bien, ise limita la burla de Juanito y Mesía a, respectivamente, Fortunata Izquierdo y Ana Ozores? De ser así, poca habría sido la aportación de nuestros dos novelistas. Lo que Galdós y Clarín hacen no es tanto contextualizar socialmente la burla donjuanesca como explicar el papel social de la burguesía española desde los parámetros de la burla donjuanesca. Que todo ello responda a una intención preestablecida resultará acaso demasiado aventurado, pero a la luz de los textos algo parece haber.

El Madrid que pinta Galdós es ámbito de confrontación entre burguesía y pueblo en el marco de la Restauración. Así como Juanito burla y abandona a Fortunata, la burguesía ha burlado el destino de un pueblo cosificado; así como Juanito ha embaucado a Fortunata con la promesa de un matrimonio que nunca llegará a contraerse, la burguesía ha profanado los ideales de la revolución septembrina. Pero si Fortunata no se resigna, acaso tampoco lo haga el pueblo. Fortunata, en conciencia, conforme a su idea, es esposa, esto es, cree contra toda razón en la posibilidad de esa unión prometida en falso por el señorito Santa Cruz. Fortunata se rebela contra la burla. Si aplicamos esto mismo a la dialéctica entre pueblo y burguesía, cobra sentido la opinión de Hurtado de Mendoza (1980: 258), para quien el propósito de Galdós es una llamada "a la concordia, a la necesaria reconciliación". La idea de Fortunata bien puede ser la de una clase popular a la que Galdós quiere dar voz ${ }^{16}$. Una clase tal vez, como ella, "llena de debilidades e impurezas, en quien la razón se halla en estado embrionario" (Pérez Galdós 1999: 497), pero que comienza a hacerse un hueco en el espectro social. Es difícil precisar hasta qué punto considera Galdós que la mujer sea, según interpreta Pilar Concejo (1993: 365), "núcleo fundamental de la nueva sociedad". En todo caso sí parece, siguiendo a esta misma autora (1993: 371), que "la mujer que se atreve a hacer algo no admitido socialmente es castigada, y la resignada es premiada". A Fortunata, como personaje individual y como emblema social, se le ha exigido resignación tras la burla. Lo han intentado las Micaelas, lo han intentado Guillermina y Nones ${ }^{17}$, y han fracasado todos. Ahora bien, lo interesante no es que hayan fracasado: lo realmente interesante es que, ante sus mismos ojos y sin que nadie se percate, Fortunata se ha transformado, ha forjado una voz propia y una conciencia que los demás no pueden comprender. Menos que nadie

15 Algo más Mesía, quien se nos presenta como alguien que a menudo "ve lo que está pensando y no lo que tiene delante" (Alas “Clarín” 1997: 381).

16 De ahí su preocupación por reproducir el habla del pueblo (v. Shoemaker 1971: 646-647).

17 Lo ha intentado, a su modo, el mismo Feijoo, trasunto de Galdós, pero ahora Fortunata, que no es ya la moza inocente de la primera parte, asume sus enseñanzas de manera crítica, siendo capaz de tomar lo que considera mejor de ellas. No es tan práctica como la quería don Evaristo pero, con todo, las enseñanzas del viejo seductor no caen en saco roto. 
Juanito, quien mejor personifica los vicios del estamento burgués. Tomándola y dejándola a su antojo, no ha sabido percatarse de "la moralidad de Fortunata, los móviles de su comportamiento, lo que ella llama ahora su conciencian, en palabras de Caudet Roca ( $v$. Pérez Galdós 1992: 74). El canario, otrora ferviente partidario de los valores que creía descubrir en la burguesía liberal ( $v$. Fuentes), muestra aquí al tiempo una decepción y una intuición: decepción porque esta burguesía se ha mostrado a la postre perniciosa para el pueblo; la intuición, sin embargo, de que el pueblo está adquiriendo, como Fortunata, una nueva conciencia.

Tan negado como Santa Cruz está Mesía para toda percepción de trascendencia: "cuando la mujer se convencía de que no había metafísica, le iba mucho mejor a don Álvaro" (Alas "Clarín” 1997: 298). El problema es que en Ana Ozores sí hay metafísica. La seduce no sólo por sus méritos, sino porque ella misma toma "plena conciencia de que no le es posible luchar contra su propia naturaleza" (Vilanova 2001: 172); y esta conquista, como a Juanito, se le escapa de las manos. Ana no es Fortunata, sino tan solo una buena mujer de cuya caída da cuenta Clarín desde una óptica naturalista (v. Vilanova 2001: 158159) ${ }^{18}$, pero también, a su modo, comprende y aprende. Esa Regenta que, recién descubierto el goce carnal, agota con sus tardías apetencias al viejo Don Juan y adquiere, ya viuda de Quintanar, noción plena de "la amargura de aquella maldad universal" (Alas "Clarín" 1997: 784) de los vetustenses, para aportar su último grano de honradez, la renuncia a la pensión de viudedad que le corresponde (Alas “Clarín" 1997: 786-787), no es un personaje tipo, o no de una manera tan obvia como Fortunata, pero no por ello está exenta de simbología social. Si Galdós ha dibujado la acción opresora de una clase, la burguesa, sobre ese pueblo llano en que, como en Fortunata, comienzan a adivinarse brotes de una nueva identidad, Clarín, eludiendo la dialéctica entre clases, ha desmenuzado la podredumbre latente en una de ellas. La caída de Ana Ozores ejemplifica todas las miserias de la doble moral burguesa, incidiendo quizás de modo más directo en la degradación de una "burguesía avasalladora, que gracias a su omnímodo poder controla todo el mundo social de la época" (Rodríguez Puértolas 1975: 55). Una burguesía que juega con los ideales liberales como quiso hacerlo Juanito con la idea de Fortunata, o Mesía con los sueños de Ana.

Pero, decíamos, Vetusta no es Madrid. El Don Juan, como el señorito burgués, es negación de la historia, y el Madrid de Fortunata es historia que se está haciendo. Galdós lo sabe, aunque desconozca el rumbo. Lo que sí conoce es que la idea de Fortunata no ha muerto con ella, como no ha muerto la de ese Maxi casi apocalíptico que clausura la obra ingresando en Leganés. ¿Hasta qué punto ha fracasado Fortunata? Es interpretable. Como representación de la clase proletaria, bien es verdad que los Santa Cruz se quedan con el fruto de su vientre, ese segundo Pitusín que aprenderá "su poquito de francés, su poquito de piano" (Pérez Galdós 1999: 67); pero, por de pronto, su transición de mero personaje-

18 Precisamente por ser una mujer buena puede, e incluso debe, caer, está predestinada a ello. No así la Fandiño: "Toda Vetusta sabía quién era Obdulia..., pero ella no había dado ningún escándalo" (Alas "Clarín" 1997: 783).

BEOIBERÍSTICA Vol. II / Número 1 (2018) | 99-112 
tipo a personaje-individuo, esto es su definitiva toma de conciencia, no tiene retorno. Como no lo tiene esa convicción suya de ser, a fin de cuentas, un ángel ( $v$. Pérez Galdós 1999: 528). Fortunata, al igual que Madrid, es historia lineal y abierta, por más que haya chocado contra el determinismo propio de los cánones naturalistas; Juanito no. Si el final de Fortunata admite, o así nos lo parece, más de una interpretación es porque Galdós ha visto en ella una alternativa cuyas últimas consecuencias se le escapan. No se le escapa, sin embargo, la superación del tipo social encarnado por Juanito: "Que espere [...]. Que tenga paciencia, que también la tienen los demás" (Pérez Galdós 1999: 505), le espetará una desconocida Jacinta al final de la novela. Todo el daño que podía hacer Juanito está hecho, pero ante sus ojos se han transformado Fortunata y Jacinta - las dos burladas - y no ha sabido verlo. Ha sido superado por la historia $y$, colmo de la parodia, no abandona la novela cabalgando tras la burla como los donjuanes de antaño, sino convertido en ese marido, ironía, a quien su esposa manda esperar. También Jacinta, que ya anda por las calles sin su permiso, es historia. Fortunata, Jacinta, el mismo Maxi Rubín, llegan al final de la novela totalmente individualizados: se diría que no gozan de tan mala salud los muertos que nuestro Don Juan ha ido matando. $Y$ él, por el contrario, ha pasado de Don Juan a donjuanito ${ }^{19}$, un personaje totalmente menor, superado por la historia.

Álvaro Mesía tiene, con todo, un final más acorde con los tópicos donjuanescos: huye para seguir seduciendo - en este caso a la ministra de Palomares (v. Alas "Clarín" 1997: 783) - dejando tras de sí una mujer deshecha y el cadáver de un marido burlado. Fortunata muere admirada por su rival - "todas deberíamos hacer lo mismo" (Pérez Galdós 1999: 504), confesará Jacinta-, mientras que de Ana "hablaban mal todas las mujeres de Vetusta, y hasta la envidiaban y despellejaban muchos hombres con alma como la de aquellas mujeres" (Alas "Clarín" 1997: 782). La destrucción completa de la Regenta, como lo es la de ese Quintanar herido de muerte vergonzante, contrasta con el Mesía que marcha a Madrid siendo, en el fondo, el mismo que comenzó la novela. Nada en él ha cambiado, como nada tampoco parece haber cambiado en Vetusta. El Magistral lo aventajaba en fuerza física, en profundidad psicológica e incluso en talla moral; don Víctor era mejor tirador, pero él es, a la postre, el único personajes de la novela que no queda destruido porque Vetusta, que no es Madrid, lo ampara. La ciudad levítica dibujada por Clarín, tan al borde de la historia aunque en constante referencia a ella, es un caldo de cultivo más propicio para los donjuanes a la vieja usanza. No hay grandeza en la huida de don Álvaro, desde luego, ni hará falta abundar en lo paródico del personaje, pero al menos, y al contrario que Santa Cruz, no ha sido engullido por la historia porque en Vetusta, en rigor, no hay tal. Qué suceda al personaje en Madrid,

19 En feliz expresión con que Rodríguez Puértolas dio su visto bueno a nuestro planteamiento. Si la memoria no falla, sus palabras fueron: "Por eso es un donjuanito". 
ahora sí el Madrid de Galdós, Fortunata y Juanito, es cosa que necesariamente se nos escapa y seguramente tampoco Clarín llegara a plantearse.

Así las cosas, Álvaro Mesía y Juanito Santa Cruz encarnan, bajo la máscara donjuanesca, esos tipos sociales cuya superación histórica anhelan tanto Galdós como Clarín, pero su inserción en dos ámbitos urbanos tan dispares da resultados distintos ${ }^{20}$. Alas ha hecho habitar a su Don Juan, negación de la historia, en una ciudad impermeable a la historia, terreno propicio para la burla; mientras que en el Madrid galdosiano, historia viva, se degrada el Delfín, apenas donjuanito que solo de manera vicaria puede participar del triunfo de su clase ${ }^{21}$ : han ganado los suyos porque, en fórmula recurrente en la novela, "quien manda, manda", pero a él en concreto, como personaje y como arquetipo, lo ha burlado la historia.

\section{BIBLIOGRAFÍA}

Acosta de Hess, Josefina. Galdós y la novela de adulterio. Madrid: Pliegos, 1988. Impreso.

Alas "Clarín”, Leopoldo. La Regenta. Ed. Mariano Baquero Goyanes. Madrid: EspasaCalpe, Nueva Colección Austral, 1997. Impreso.

Andreu, Alicia G. "Juanito Santa Cruz en diálogo con el mito de don Juan". Revista Hispánica Moderna, 42 (1989): 3-18. Impreso.

Beser, Sergio (ed.). Clarín y La Regenta. Barcelona: Ariel, 1982. Impreso.

Beyrie, Jacques. Galdós et son mythe. Romantisme et sources vives du "naturalisme" galdosien (1860-1880). Vol. II. Lille: Atelier Reproduction des Theses. Université de Lille, 1980. Imprimé.

Cañas, José Luis. Sören Kierkegaard. Entre la inmediatez y la relación. Madrid: Editorial Trotta, 2003. Impreso.

Caudet Roca, Francisco. El parto de la modernidad. La novela española en los siglos XIX y $X X$. Madrid: Ediciones de la Torre, 2002. Impreso.

-. "Las grandes novelas I (1881-1885)". VV.AA. Madrid en Galdós. Galdós en Madrid. Madrid: Dirección General de Patrimonio Cultural, 1988: 271-287. Impreso.

Chamberlain, Vernon A. "Juan Valera y la caracterización de Juanito Santa Cruz en Fortunata y Jacintan. Actas del IX Congreso de la Asociación Internacional de Hispanistas, Berlín, Frankfurt am Main, Vervuert: 1989: 1237-1242. Web. 17 Jun. 2017.

Concejo, Pilar. "Lo femenino como mito en Galdós". Actas del cuarto congreso internacional de estudios galdosianos (1990), vol. II, Las Palmas de Gran Canaria: Ediciones del Cabildo Insular de Gran Canaria, 1993: 365-375. Impreso.

20 Imagínese una ordenación a la manera de tríada dialéctica donde el Don Juan ocupara el lugar de la tesis y la ciudad viniera a ser antítesis: si cambiamos la ciudad, cambiamos necesariamente la síntesis.

${ }^{21}$ Suyo, o de los suyos, será el Pitusín segundo.

BEOIBERÍSTICA Vol. II / Número 1 (2018) | 99-112 
Fernández Gutiérrez, José María. "Función de los objetos de interiores". Clarín y La Regenta en su tiempo. Actas del simposio internacional [Oviedo, 1984], Oviedo, 1987: 431-439. Impreso.

Fuentes, Víctor. "Notas sobre el realismo en "Observaciones sobre la novela contemporánea en España”.. Anales galdosianos, X (1975): 123-125. Alicante: Biblioteca Virtual Miguel de Cervantes. Web. 17 Jun. 2017.

Gies, David T. "Don Juan contra Don Juan: Apoteosis del romanticismo español”. Actas del séptimo Congreso de la Asociación Internacional de Hispanistas [Venecia: 1980], Roma: Bulzoni, 1982: 545-551. Web. 17 Jun. 2017.

Gold, Hazel. "De paso por el museo: sociedad y conocimiento en La Regenta de Clarín". Actas del X Congreso de la Asociación Internacional de Hispanistas [Barcelona: 1989], Vol. 2, Barcelona, 1992: 1285-1294. Web. 17 Jun. 2017.

Hurtado de Mendoza, A. "Necesidad de un estudio socio-cronológico de la obra de Pérez Galdós". Actas del Segundo Congreso Internacional de Estudios Galdosianos, Vol. II, Las Palmas de Gran Canaria, 1980: 257-269. Impreso.

Lissorgues, Yvan. La pensée philosophique et religieuse de Leopoldo Alas (Clarín). 1875 1901. Paris: Centre National de la Recherche Scientifique, 1983. Imprimé.

Montesinos, José F. Galdós. Vol. II. Madrid: Castalia, 1980. Impreso.

Mora García, José Luis. Hombre, sociedad y religión en la novelística galdosiana (18881905). Salamanca: Ediciones Universidad, 1981. Impreso.

Pérez Galdós, Benito. Fortunata y Jacinta. Tomo I. Ed. Francisco Caudet. Madrid, Cátedra, 1992. Impreso.

- Fortunata y Jacinta. Tomo II. Ed. Francisco Caudet. Madrid, Cátedra, 1999. Impreso.

-. "Teatro Real. Don Giovannin. La Nación (29/01/1868). Microfilm Biblioteca Nacional de España.

Rodríguez Puértolas, Julio. "Fortunata y Jacinta”. VV.AA. Madrid en Galdós. Galdós en Madrid. Madrid: Dirección General de Patrimonio Cultural, 1988. 289-298. Impreso.

—. Galdós: Burguesía y revolución. Madrid: Turner, 1975. Impreso

-. "Realismo, realismos, realidad: entre espejos anda el juego". Príncipe de Viana, Anejo, 18 (2000): 319-329. Impreso.

Seco Serrano, Carlos. Sociedad, literatura y política en la España del s. XIX. Madrid: Guadiana, 1973. Impreso.

Shoemaker, W. H. "Problemas galdosianos sin resolver". Actas del Cuarto Congreso de la Asociación Internacional de Hispanistas [Salamanca, 1971], Salamanca, 1982: 645653. Impreso.

Ubach Medina, Antonio. "Don Juan y La Regenta". Espéculo. Revista de Estudios Literarios. Web. 17 Jun. 2017. 
Vilanova, Antonio, "La Regenta de Clarín entre la ley natural y el deber moral". Clarín y La Regenta en su tiempo. Actas del simposio internacional, Oviedo, 1987: 353383. Impreso.

—. Nueva lectura de "La Regenta" de Clarín. Barcelona: Anagrama, 2001. Impreso. Vossler, Karl. Lecciones sobre Tirso de Molina. Madrid: Taurus, 1995. Impreso.

Fecha de recepción: 05 de diciembre de 2017. Fecha de aceptación: 12 de abril de 2018. 